\title{
PREFERENSI KONSUMEN PADA PRODUK Gumdrops Puree PEPAYA CALINA IPB
}

\author{
H. Ramdani ${ }^{1 a}$ dan M. Lesmanasari ${ }^{2}$ \\ ${ }^{1}$ Pengajar PS Ilmu dan Teknologi Pangan, Fakultas Bioindustri, Universitas Trilogi, \\ Peneliti Pusat Kajian Hortikultura Tropika (PKHT) Institut Pertanian Bogor \\ ${ }^{2}$ Jurusan Teknologi Industri Pertanian, Fakultas Ilmu Pangan Halal, Universitas Djuanda \\ Bogor \\ ${ }^{a}$ Korespondensi: Hisworo Ramdani; E-mail: hisworor@gmail.com
}

\begin{abstract}
The aim of this research is to analyze the relantions of respondent's characteristics with candy's consumption and determine quality of attributes to require improvement before entry to the scale industry level. This research used Kruskal-Wallis method to test the characteristics of respondent toward candy consumption level and Fishbein multi-attribute to determine attribute of papaya gumdrops puree. Based on this research, the respondents characteristics consist of the age, gender, status, formal or informal education, occupation and expenditure per month. The results leveled, that the age and occupation, effect significant of consumption level. Based on the analysis result of Fishbein multi-attribute, the confidence score (bi) showed the taste, fragrant and texture attruibutes is more preferred by consumer, while the score evaluation (ei) showed colour and testure attributes is more preferred consumer.
\end{abstract}

Keywords: Papaya Gumdrops Puree, Papaya Calina IPB, Preferences Analysis

\begin{abstract}
ABSTRAK
Penelitian ini bertujuan untuk menganalisis hubungan antara karakteristik responden dengan tingkat konsumsi permen, mengidentifikasi evaluasi responden terhadap atribut mutu produk gumdrops puree pepaya dan mengidentifikasi atribut-atribut mutu yang perlu mendapat perbaikan sebelum masuk ke tahap scale-upindustry. Metode yang digunakan adalah metode kruskal wallis untuk menguji karakteristik responden terhadap tingkat konsumsi permen dan multi atribut fishbein untuk menguji atribut gumdrops puree pepaya. Berdasarkan hasil penelitian, karakteristik responden terdiri dari usia, jenis kelamin, status menikah, pendidikan, pekerjaan dan pendapatan per bulan. Hasil pengujian menggunakan metode kruskal wallis, usia dan pekerjaan berpengaruh nyata terhadap tingkat konsumsi. Berdasarkan hasil analisis multiatribut fishbein, pada skor kepercayaan (bi) atribut rasa, aroma dan tekstur yang lebih disukai oleh respnden sedangkan pada skor evaluasi (ei) atribut warna dan tekstur yang lebih disukai oleh responden.
\end{abstract}

Kata kunci: Gumdrops puree pepaya, pepaya calina IPB, Analisis Preferensi. 


\section{PENDAHULUAN}

Gumdrops merupakan salah satu jenis permen lunak (soft candy) yang memiliki kesamaan dengan permen jelly, diproses dengan penambahan komponen hidrokoloid seperti agar, gum, pektin, pati, karagenan, gelatin, dan lain-lain yang digunakan untuk modifikasi tekstur sehingga menghasilkan produk yang kenyal. Gumdrops sangat disukai oleh semua usia terutama oleh anakanak karena rasanya yang manis, tekstur kenyal dan warna yang menarik.

Bahan utama yang umum digunakan dalam pembuatan gumdrops adalah gelatin sebagai bahan pengental, gelatin yang digunakan berasal dari kulit dan tulang hewan babi $40 \%$ dan sapi $60 \%$, di Indonesia gelatin masih merupakan bahan impor, dimana pengekspor utamanya adalah Eropa dan Amerika (Pusat Data dan Informasi Deperindag, 2004). Rasa manis dan warnawarna yang menarik pada pembuatan gumdrops menjadi suatu permasalahan, rasa manis yang berasal dari perisa buatan dan warna makanan yang digunakan. Nilai gizi gumdrops masih kurang, apalagi gumdrops sangat disukai terutama oleh kalangan anakanak. Jika dilihat dari segi kualitas nilai gizi gumdrops tidak diperhatikan.

Pepaya merupakan buah yang kaya manfaat dengan harga terjangkau, banyak mengandung vitamin A dan vitamin $\mathrm{C}$ serta penghasil papain. Pepaya yang sedang diminati konsumen dan permintaannya yang tinggi saat ini yaitu Pepaya Calina IPB. Penelitian mengenai preferensi konsumen produk gumdrops berbahan dasar puree papaya ini dilakukan untuk melihat tingginya peluang pengembangan sebagai alternatif jajanan yang berkualitas.

Gumdrops merupakan jenis soft candy yang berbahan dasar gelatin yang masih diragukan kehalalannya karena gelatin yang digunakan terbuat dari kulit dan tulang hewan babi dan sapi. Pada proses pembuatan gumdrops, rasa manis dan warna-warna yang menarik pada gumdrops menjadi suatu permasalahan, rasa manis yang berasal dari perisa buatan dan pewarna makanan yang digunakan. Pengembangan produk gumdrops berbahan puree pepaya dan menggunakan agar-agar perlu mengutamakan kesesuaian dengan karakteristik, keinginan dan kebutuhan konsumen.

Berdasarkan permasalahan yang telah diuraikan diatas, maka tujuan dari penelitian ini adalah menganalisis hubungan antara karakteristik responden dengan tingkat konsumsi permen, mengidentifikasi evaluasi responden terhadap atribut mutu produk gumdrops puree pepaya dan atribut-atribut mutu yang perlu mendapat perbaikan sebelum masuk ke tahap scale-upindustry.

Ruang lingkup penelitian ini antara lain menganalisa hubungan antara karakteristik respondendengan tingkat konsumsi permen, tingkat kesukaan konsumen terhadap produk gumdrops puree pepaya. Sekaligus menganalisa persepsi atau tanggapan konsumen terhadap produkgumdrops puree pepaya. Hal ini dimaksudkan agar dapat memberikan gambaran untuk mengevaluasi produk gumdrops puree pepaya terutama yang berkaitan dengan kualitas gumdrops puree pepaya. Pengamatan ini dilakukan pada konsumen dengan cara melakukan uji organoleptik (kesukaan) terhadap gumdropspuree pepaya dan gumdrops sebagai kontrol.

\section{BAHAN DAN METODE}

Produk gumdrops berbahan dasar puree pepaya adalah produk yang relatif baru dalam produksi gumdrops, kecuali untuk produksi soft candy lain. Produk gumdrops yang beredar di pasaran saat ini sebagian besar berbahan dasar gelatin, perisa buah dan pewarna makanan. Pengembangan produk gumdrops berbahan puree pepaya dan agar perlu mengutamakan kesesuaian dengan karakteristik, keinginan dan kebutuhan konsumen. Preferensi dan tingkat penerimaan produk gumdrops oleh responden dipengaruhi oleh banyak faktor maka pada penelitian ini faktor yang dianalisis adalah karakteristik responden ((jenis kelamin, usia, status menikah, tingkat pendidikan, pekerjaan dan pengeluaran belanja per bulan) dan faktor mutu produk gumdrops puree pepaya(rasa, warna, kepadatan, tekstur, aroma).

\section{Waktu dan Tempat}

Lokasi penelitian ini adalah di Bogor Selatan, Kota Bogor, Jawa Barat. Kegiatan 
penelitian dilakukan selama tiga bulan yaitu dari bulan Maret 2013 sampai dengan Mei 2013. Penelitian ini mengumpulkan dan mengolah data dari dua jenis data yaitu data primer dan data sekunder. Data primer merupakan data yang diperoleh melalui pengamatan langsung di lapangan. Data sekunder mencakup data kependudukan dan data keadaan lokasi yang diperoleh melalui Badan Pusat Statistik Kota Bogor, dan beberapa sumber data lain yang diperlukan untuk mendukung hasil penelitian ini. Sebelum kuesioner sebenarnya disebarkan kepada responden dilakukan pengujian terlebih dahulu dengan pretest dilakukan untuk menyempurnakan kuisioner. Pretest dilakukan dengan menyebarkan beberapa kuesioner dan responden yang dipilih adalah responden yang dapat dihubungi kembali. Uji coba kuesioner dilakukan pada 30 responden. Setelah selang waktu 20 hari, kuesioner disebarkan kembali pada responden yang sarna. Setelah itu perlu dilakukan uji validitas digunakan untuk mengukur keshahihan suatu alat ukur. Reliabilitas merupakan konsistensi alat ukur dalam mengukur gejala yang sama untuk mengetahui tingkat kesahihan pengukuran. Jumlah sampel ditentukan dengan menggunakan rumus Slovin (Umar 2000), sebagai berikut :

$n=\frac{N}{1+N e^{2}}$

Keterangan :

$$
\begin{array}{ll}
\mathrm{n} & \text { : jumlah sampel } \\
\mathrm{e} & \text { : persen kelonggaran } \\
\mathrm{N} & : \text { ukuran populasi }
\end{array}
$$

\section{Metode Analisis Data}

Menurut Singarimbun (2006), analisis data adalah proses penyederhanaan data dalam bentuk yang lebih mudah dibaca dan dinterpretasikan. Data primer yang terkumpul akan dianalisis secara kualitatif dan kuantitatif. Data yang berkaitan dengan karakteristik responden akan diolah secara kualitatif (deskriptif) yang disajikan dalam bentuk tulisan, tabel dan diagram. Sedangkan data yang berkaitan dengan preferensi konsumen akan diolah dan dianalisis secara kuantitatif.

1. Analisis Kruskal Wallis
Uji Kruskall Wallis merupakan uji non parametrik yang menggunakan analisa statistik untuk menguji hubungan karakteristik responden (terdiri dari 3 variabel atau lebih) dengan tingkat konsumsi produk. Uji Kruskall Wallis dijabarkan dengan perhitungan sebagai berikut :

$$
H=\frac{12}{N(N+1)} \sum_{j=1} \frac{R_{j}{ }^{2}}{n_{j}}-3(N+1)
$$

Keterangan :

nj : jumlah seluruh pengamatan, j sampel $\mathrm{N}$ : jumlah seluruh pengamatan dari sampel $\mathrm{Rj}$ : jumlah ranking dalam $\mathrm{j}$ sampel

\section{Analisis Multiatribut Fishbein}

Diketahui suatu produk dengan atribut tertentu ternyata tidak memenuhi atribut ideal yang diharapkan konsumen, maka pemasar perlu mengembangkan produk tersebut dengan atribut yang sesuai dengan bentuk ideal yang diharapkan. Secara simbolis, model sikap Fishbein (Sumarwan, 2002). Pada model sikap fishbein terdapat dua komponen penting dalam pengukuran sikap konsumen, yaitu adanya evaluasi dan belief yang ada pada diri konsumen terhadap sebuah obyek tertentu. Rumus model Fishbein adalah sebagai berikut:

$$
A_{0}={ }_{i=l}^{n} b_{i} e_{i}
$$

Keterangan :

A0 : sikap terhadap produk

$\mathrm{Bi}$ : kekuatan keyakinan terhadap atribut ke-i ei : skor evaluasi atribut ke-i

$\mathrm{n}$ : jumlah atribut yang menonjol 


\section{HASIL DAN PEMBAHASAN}

\section{Uji Reliabilitas dan Validitas Kuisioner}

Berdasarkan hasil uji reliabilitas, semua pertanyaan dapat dikatakan reliabel, diperoleh nilai rataan alpha cronbach diperoleh sebesar 0,732 lebih besar dari 0,6. Pada hasil uji validitas, terlihat semua pertanyaan dikatakan valid, karena peubah tersebut sangat nyata pada level 0,01 dan nyata pada level 0,05 , dimana $r_{\text {hitung }}$ lebih besar dari $r_{\text {tabel. }}$.

Tabel 1. Uji reliabilitas kuisioner

\begin{tabular}{ccc}
\hline $\begin{array}{c}\text { Rataan } \\
\text { Cronbach's } \\
\text { Alpha }\end{array}$ & $\begin{array}{c}\text { Jumlah } \\
\text { pertanyaan }\end{array}$ & Status \\
\hline 0,732 & 17 & Reliabel \\
\hline
\end{tabular}

Tabel 2. Uji validitas kuisioner

\begin{tabular}{|c|c|c|c|c|}
\hline Pertanyaan & \multicolumn{2}{|c|}{$\mathrm{r}_{\text {hitung }}$} & $\mathrm{r}_{\text {tabel }}$ & Status \\
\hline 3 & \multicolumn{2}{|c|}{0,426} & 0,361 & Valid \\
\hline 4 & \multicolumn{2}{|c|}{0,655} & 0,361 & Valid \\
\hline 5 & \multicolumn{2}{|c|}{0,676} & 0,361 & Valid \\
\hline 6 & \multicolumn{2}{|c|}{0,495} & 0,361 & Valid \\
\hline 7 & \multicolumn{2}{|c|}{0,55} & 0,361 & Valid \\
\hline 8 & 0,528 & 0,361 & \multicolumn{2}{|c|}{ Valid } \\
\hline 9 & 0,554 & 0,361 & \multicolumn{2}{|c|}{ Valid } \\
\hline 11 & 0,409 & 0,361 & \multicolumn{2}{|c|}{ Valid } \\
\hline 12 & 0,785 & 0,361 & \multicolumn{2}{|c|}{ Valid } \\
\hline 13 & 0,454 & 0,361 & \multicolumn{2}{|c|}{ Valid } \\
\hline 14 & 0,555 & 0,361 & \multicolumn{2}{|c|}{ Valid } \\
\hline 15 & 0,615 & 0,361 & \multicolumn{2}{|c|}{ Valid } \\
\hline 16 & 0,671 & 0,361 & \multicolumn{2}{|c|}{ Valid } \\
\hline 17 & 0,629 & 0,361 & \multicolumn{2}{|c|}{ Valid } \\
\hline 18 & 0,464 & 0,361 & \multicolumn{2}{|c|}{ Valid } \\
\hline 19 & 0,529 & 0,361 & \multicolumn{2}{|c|}{ Valid } \\
\hline 20 & 0,628 & 0,361 & \multicolumn{2}{|c|}{ Valid } \\
\hline
\end{tabular}

\section{Karakteristik Responden Jenis Kelamin dan Usia}

Berdasarkan jenis kelamin, kebanyakan responden berjenis kelamin perempuan (63\%) dan selebihnya laki-laki (37\%) dapat dilihat pada gambar 1 .

\section{Sebaran Jenis Kelamin Responden}

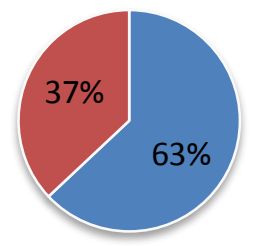

- Perempuan

- Laki-laki

Gambar 1. Sebaran jenis kelamin responden

Hal ini menjelaskan bahwa perempuan lebih banyak mengkonsumsi produk gumdrops puree pepaya dibandingkan laki-laki, namun demikian bukan berarti konsumen gumdrops puree pepaya dipengaruhi oleh faktor jenis kelamin. Hal ini terjadi karena faktor kebetulan dan ketersediaan elemen yang bersedia untuk menjadi responden dalam penelitian ini. Pada tingkat usia dapat dilihat pada Gambar 2, secara keseluruhan responden dalam kategori usia produktif. Rata-rata responden berusia 22 tahun dengan sebaran antara usia 14 tahun sampai dengan usia 58 tahun.

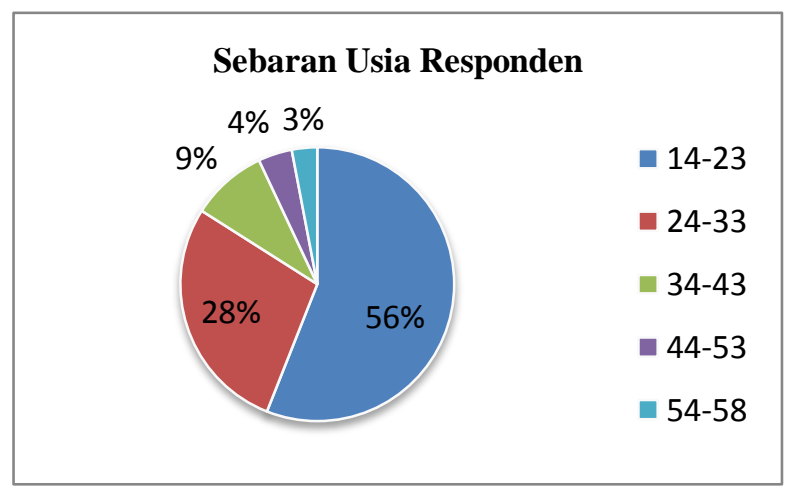

Gambar 2. Sebaran usia responden

\section{Status Menikah}

Berdasarkan status menikah, responden yang belum menikah (70\%), sudah menikah (29\%) dan selebihnya janda (1\%). Karakteristik responden berdasarkan status menikah disajikan pada gambar 3 . 


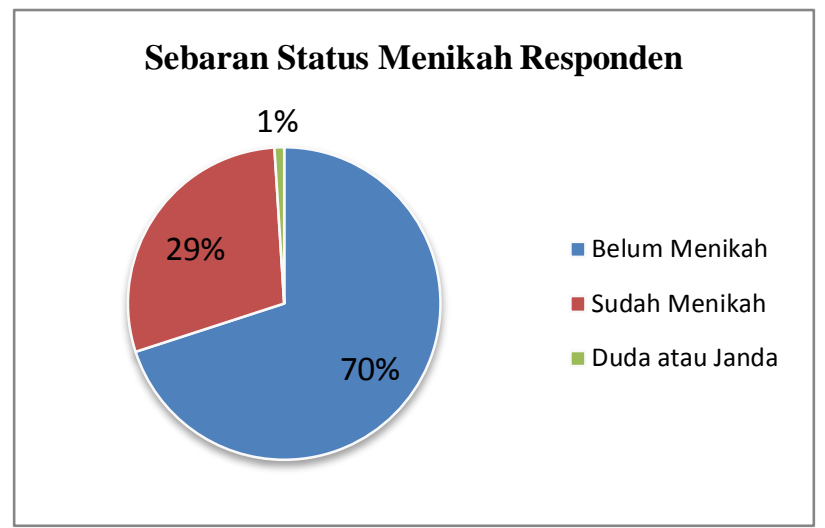

Gambar 3. Sebaran status menikah responden

\section{Pekerjaan}

Berdasarkan jenis pekerjaan responden yang cukup mendominasi adalah pelajar atau mahasiswa (41\%), pegawai swasta (23\%), lainnya adalah guru honor (17\%) dan selebihnya wiraswta (11\%), PNS (5\%) dan belum bekerja (3\%). Sebaran pekerja responden dapat dilihat pada Gambar 4.

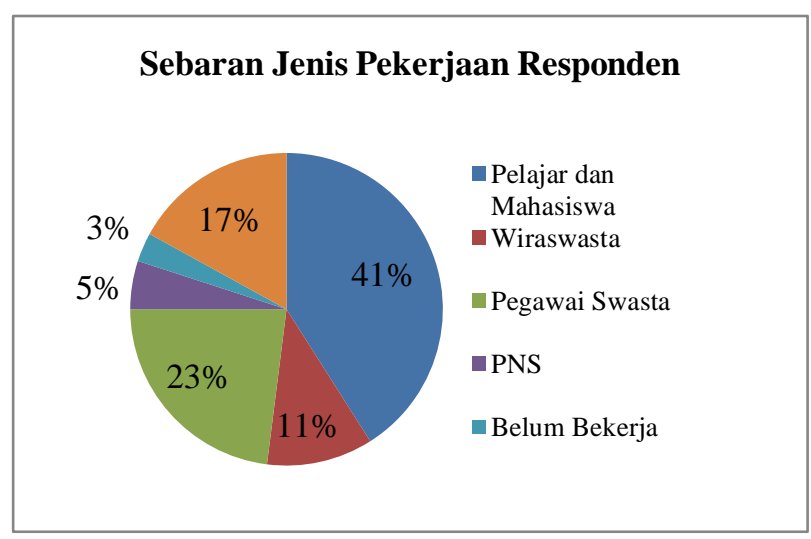

Gambar. 4 Sebaran Jenis Pekerjaan Responden

\section{Penididikan Terakhir}

Berdasarkan pendidikan terakhir, responden yang mendominasi adalah responden yang berpendidikan terakhir SMA yaitu (52\%), D3 (20\%), lainnya adalah S1 (15\%), SMP (13\%) dan $(0 \%)$ untuk SD. Sebaran pendidikan teakhir responden dapat dilihat pada Gambar 5.

\section{Sebaran Pendidikan Responden}

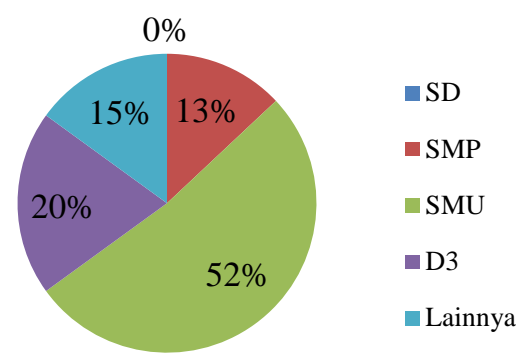

Gambar 5. Sebaran Pendidikan Responden

\section{Pengeluaran Belanja Per bulan}

Berdasarkan pendapatan rataan per bulan, responden yang mendominasi adalah responden yang berpendapatan rataan per bulan < Rp. 500.000,- (51\%), Rp 500.000,- - Rp. 1000.000,- (17\%) dan > Rp. 1000.000 (32\%). Sebaran pendapatan per bulan responden dapat dilihat pada Gambar 6.

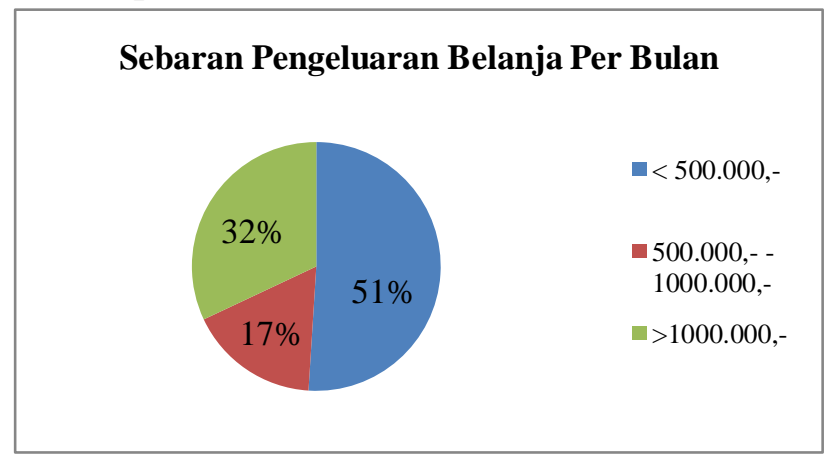

Gambar 6. Sebaran Pengeluaran Belanja Per Bulan

\section{Hubungan Tingkat Konsumsi Responden Dengan Karakteristik Responden}

Produk gumdrops puree pepaya ditujukan untuk responden dengan tidak dibatasi oleh usia, jenis kelamin, status menikah, jenis pekerjaan, pendidikan terakhir dan pengeluaran belanja per bulan yang dihubungkan dengan tingkat konsumsi permen responden. Hasil perhitungan dengan menggunakan metode kruskal wallis dapat dilihat pada tabel 3. 
Tabel 3. Hasil uji statistik hubungan tingkat konsumsi permen dengan karakteristik responden

\begin{tabular}{rlc}
\hline No & Karakteristik Responden & $\begin{array}{c}\text { Nilai } \\
\text { Signifikan }\end{array}$ \\
\hline 1 & Usia & 0,039 \\
2 & Jenis kelamin & 0,398 \\
3 & Status menikah & 0,143 \\
4 & Jenis pekerjaan & 0,01 \\
5 & Pendidikan terakhir & 0,054 \\
& Pengeluaran belanja per & 0,072 \\
6 & bulan & \\
\hline
\end{tabular}

Berdasarkan hasil uji menggunakan metode kruskal wallis, usia dan jenis pekerjaan berhubungan secara nyata terhadap tingkat konsumsi permen responden. Hasil yang diperoleh angka probabilitas (Asymp. Sig) dimana angka probabilitas usia $(0,039)$ dan jenis pekerjaan $(0,010)$ karena $p$ lebih kecil daripada tingkat signifikasi $(0,05)$ maka H0 ditolak. Menurut (Kotler dan Kevin 2008) prilaku konsumen dipengaruhi oleh tiga faktor yaitu (1) faktor individu, (2) faktor lingkungan dan (3) faktor psikologis. Faktor individu meliputi usia dan tahapan dalam siklus hidup pembeli ; pekerjaan dan keadaan ekonomi ; kepribadian dan konsep diri ; serta gaya hidup dan nilai. Selera konsumen dalam membeli produk slalu berhubungan dengan usia. konsumen membeli barang dan jasa yang berbeda sepanjang hidupnya.

Jenis pekerjaan yang ditekuni sebagai profesi akan menimbulkan pola konsumsi dan gaya hidup beraneka ragam yang disesuaikan dengan kondisi masing-masing untuk memenuhi apa yang diinginkan sehingga dapat menimbulkan diferensiasi pada suatu produk (Kotler 1997).

\section{Atribut-atribut yang Mempengaruhi Pembelian Produk Gumdrpos Puree Pepaya}

\section{Analisis Tingkat Kepentingan (evaluation)}

Skor evaluasi menggambarkan pentingnya suatu atribut bagi konsumen, karena konsumen akan mengidentifikasi atribut-atribut yang dimiliki oleh obyek yang dievaluasinya.
Responden yang dipilih adalah 100 orang berdasarkan rumus sloven, namun dari hasil penyebaran kuisioner yang diuji menggunakan metode fishbein adalah 90 orang, hal tersebut dikarenakan responden yang dapat melanjutkan isi kuisioner ke pertanyaan selanjutnya mengenai gumdrops puree pepaya syaratnya pernah mengkonsumsi gumdrops, selebihnya 10 orang dikatakan blanko karena belum pernah mengkonsumsi gumdrops.

Berdasarkan hasil perhitungan menunjukan bahwa atribut warna memiliki skor ei tertinggi $(3,52)$ karena warna yang digunakan berasal dari perisa buatan sehingga warnanya lebih mencolok dibandingkan warna pada gumdrops puree pepaya. Maka dianggap sebagai atribut yang paling penting dan diinginkan oleh konsumen. Atribut penting kedua menurut evaluasi konsumen adalah tekstur, yaitu skor ei $(3,51)$, teksturnya yang lembut menjadi atribut paling penting kedua dan diinginkan oleh konsumen. Atribut penting ketiga adalah rasa, yaitu skor ei $(3,50)$, rasa yang digunakan pada gumdrops umumnya menggunakan perisa buah yang memilika banyak aneka macam rasa buah. Perolehan terkecil oleh atribut aroma memperoleh $(2,9)$, hal ini disebabkan aroma pada gumdrops berasal dari perisa buah, dimana aromanya tidak dapat bertahan lama dan tidak menimbulkan wangi buah yang khas.

Tabel. 4 Frekuensi skor tingkat evaluasi (bi) atribut konsumen produk gumdrops

\begin{tabular}{|c|c|c|c|c|c|c|c|}
\hline \multirow{2}{*}{ No } & \multirow{2}{*}{ Atribut } & \multicolumn{5}{|c|}{$\begin{array}{c}\text { Frekuensi Pada Nilai Setiap } \\
\text { Skala } \\
\end{array}$} & \multirow{2}{*}{$\begin{array}{c}\text { Skor } \\
\text { Evaluasi } \\
\quad(\text { ei) }\end{array}$} \\
\hline & & 1 & 2 & 3 & 4 & 5 & \\
\hline 1 & Rasa & 1 & 1 & 40 & 48 & 0 & 3,50 \\
\hline 2 & Warna & 0 & 7 & 30 & 52 & 1 & 3,52 \\
\hline 3 & Aroma & 3 & 20 & 51 & 15 & 1 & 2,90 \\
\hline 4 & Kepadatan & 1 & 10 & 31 & 48 & 0 & 3,40 \\
\hline 5 & Tekstur & 0 & 5 & 34 & 51 & 0 & 3,51 \\
\hline
\end{tabular}

\section{Analisis Tingkat Kepercayaan (belief)}

Berdasarkan hasil perhitungan didapatkan perolehan skor terbesar diantara kelima atribut, yaitu atribut warna memiliki skor bi sebesar $(3,84)$, skor tersebut telah melebihi atribut warna pada skor ei sebesar 
$(3,50)$, hal tersebut menjelaskan bahwa atribut rasa gumdrops puree pepaya telah diterima oleh konsumen dan rasa gumdrops puree pepaya lebih disukai oleh konsumen.

Perolehan kedua adalah atribut aroma memiliki skor bi sebesar $(3,54)$, skor tersebut telah melebihi atribut aroma pada skor ei sebesar (2,90), hasil tersebut menjelaskan bahwa atribut aroma gumdrops puree pepaya telah diterima oleh konsumen dan aroma gumdrops puree pepaya lebih disukai oleh konsumen.

Atribut perolehan ketiga yaitu atribut tekstur memiliki skor bi sebesar $(3,53)$, dibandingkan pada skor ei untuk atribut tekstur memiliki skor sebesar $(3,51)$, skor tersebut menjelaskan bahwa atribut tekstur gumdrops puree pepaya telah diterima oleh konsumen dan tekstur gumdrops puree pepaya lebih disukai oleh konsumen.

Atribut selanjutnya adalah atribut warna memiliki skor bi sebesar $(3,40)$, skor tersebut berbeda pada atribut rasa, aroma dan tekstur, dimana hasil skor atribut warna kurang dari atribut warna pada skor ei sebesar $(3,52)$, hasil tersebut menjelaskan bahwa atribut warna gumdrops puree pepaya masih perlu perbaikan.

Atribut kelima adalah atribut kepadatan memiliki skor bi sebesar $(3,25)$, skor tersebut kurang dari skor atribut kepadatan pada skor ei sebesar $(3,40)$, hasil tersebut menjelaskan bahwa atribut kepadatan gumdrops puree pepaya masih perlu perbaikan.

Tabel 5. Frekuensi skor tingkat kepercayaan (bi) atribut konsumen gumdrops puree papaya

\begin{tabular}{cccccccc}
\hline \multirow{2}{*}{$\begin{array}{c}\text { o } \\
\text { Atribut }\end{array}$} & \multicolumn{5}{c}{$\begin{array}{c}\text { Frekuensi Pada Nilai } \\
\text { Setiap Skala }\end{array}$} & $\begin{array}{c}\text { Skor } \\
\text { kepercayaan } \\
\text { (bi) }\end{array}$ \\
\hline 1 & $\mathbf{1}$ & $\mathbf{2}$ & $\mathbf{3}$ & $\mathbf{4}$ & $\mathbf{5}$ & $3,84 *$ \\
2 & Rasa & 0 & 2 & 15 & 67 & 6 & 3,40 \\
3 & Warna & 0 & 16 & 36 & 44 & 2 & 3,54 \\
4 & Kepadatan & 1 & 14 & 39 & 33 & 3 & 3,25 \\
5 & Tekstur & 0 & 6 & 30 & 53 & 1 & 3,53 \\
\hline Ket $:$ & $(1 * 1+2 * 1+3 * 40+4 * 48+5 * 0) / 90,10$ & responden blanko
\end{tabular}

\section{Analisis Sikap Konsumen}

Nilai sikap konsumen untuk produk gumdrops puree pepaya didapatkan setelah mengalikan antara skor evaluasi kepentingan (ei) masing-masing atribut dengan skor kepercayaan (bi). Apabila nilai sikap untuk masing-masing atribut dijumlahkan maka akan didapat nilai sikap secara keseluruhan untuk konsumen gumdrops puree pepaya.

Tabel 6. Hasil analisis sikap multiatribut fishbein terhadap konsumen

\begin{tabular}{|c|c|c|c|c|}
\hline \multirow{2}{*}{$\begin{array}{l}\mathbf{N} \\
\mathbf{0}\end{array}$} & \multirow[t]{2}{*}{ Atribut } & \multirow{2}{*}{$\begin{array}{c}\text { Skor } \\
\text { Evaluasi } \\
(\text { ei) }\end{array}$} & \multirow{2}{*}{$\begin{array}{c}\text { Skor } \\
\text { Kepercayaan } \\
\text { (bi) } \\
\end{array}$} & \multirow{2}{*}{$\begin{array}{c}\begin{array}{c}\text { Sikap } \\
\text { Konsumen }\end{array} \\
\text { A० }(\text { eixbi }) \\
\end{array}$} \\
\hline & & & & \\
\hline 1 & Rasa & 3,5 & 3,84 & 13,475 \\
\hline 2 & Warna & 3,52 & 3,4 & 11,968 \\
\hline 3 & Aroma & 2,9 & 3,54 & 10,266 \\
\hline 4 & Kepadatan & 3,4 & 3,25 & 11,050 \\
\hline \multirow[t]{2}{*}{5} & Tekstur & 3,51 & 3,53 & 12,3903 \\
\hline & & ei $x$ bi & & 59,1493 \\
\hline kon & $\begin{array}{l}\text { Ao } \\
\text { ruhan } \\
\text { tahui } \\
\text { men }\end{array}$ & $\begin{array}{l}\text { (Sikap } \\
\text { tersebut } \\
\text { skala } \\
\text { erhadap }\end{array}$ & $\begin{array}{c}\text { Konsumen) } \\
\text { digunakan } \\
\text { penilaian } \\
\text { atribut }\end{array}$ & $\begin{array}{r}\text { secara } \\
\text { untuk } \\
\text { sikap } \\
\text { produk }\end{array}$ \\
\hline
\end{tabular}
gumdrops puree pepaya. Untuk mengetahui kategori sikap konsumen terhadap produk gumdrops puree pepaya ditetapkan skala interval, perhitungannya sebagai berikut :

$$
\text { Skala Interval }=>\frac{(125-5)}{5}=24
$$

Skala maksimum diperoleh dari (skor kepentingan $\mathrm{x}$ skor kepercayaan $\mathrm{x}$ jumlah atribut), yaitu $5 \times 5 \times 5=125$, sedangkan skor minimum diperoleh dari jumlah atribut, yaitu 5. Hasil perhitungan lengkapnya dari skala interval berikut :

- 5-29 : Sangat tidak baik

- 30-54 : Tidak baik

- 55-79: Cukup

- 80-104: Baik

- $105-129$ : Sangat baik

Berdasarkan skala interval di atas, dapat diketahui bahwa sikap konsumen terhadap produk gumdrops puree pepaya yang memiliki skor 59,1493, berada diantara interval 55 - 79. Hal ini menunjukan produk gumdrops puree pepaya dinilai "Cukup" oleh responden.

Responden yang dipilih adalah 100 orang berdasarkan rumus slovin namun 
terdapat $10 \%$ konsumen yang tidak memilih meneruskan isi kuisioner ke pertanyaan selanjutnya, hal tersebut dikarenakan konsumen belum pernah mengkonsumsi gumdrops dan konsumen lebih menyukai permen jenis hard candy. Ketika konsumen harus memilih suatu produk yang paling disukai merasakannya, apabila dari sebagian konsumen menolak atau tidak menyukai suatu produk, hal tersebut dikarenakan konsumen tidak tahu akan manfaat dari suatu produk. Menurut Teori Freud menyatakan bahwa "kekuatan psikologis yang membentuk prilaku seseorang sebagian besar adalah ketidaksadaran dan bahwa seseorang tidak dapat memahami secara penuh motivasinya sendiri. Ketika seorang mengamati merek tertentu, tidak hanya bereaksi terhadap kemampuan yang dinyatakan produk tersebut, tetapi juga terhadap tanda lain yang kurang disadari seperti bentuk, ukuran, berat, bahan, warna dan merek".

\section{Permintaan Konsumen Terhadap Gumdrops Puree Pepaya}

\section{Atribut Rasa}

Atribut rasa pada gumdrops puree pepaya memiliki skor kepercayaan (bi) sebesar 3,8 (cukup). Berdasarkan hasil terebut tidak berbeda jauh dengan produk permen jelly hasil penelitian (Yani 2006) yang menggunakan rumput laut sebagai pembentuk jel dengan metode yang digunakan yaitu uji hedonik. Skor rasa yang diperoleh untuk permen jelly rumput laut yaitu 5,25 yang artinya cukup. Skala pengukuran yang digunakan permen jelly yaitu 1 sampai 9 . Pernyataan tersebut menjelaskan bahwa produk gumdrops puree pepaya memiliki nilai rasa yang sama dengan permen jelly rumput laut.

\section{Atribut Warna}

Atribut aroma memiliki skor kepercayaan (bi) sebesar 3,54 yang artinya cukup, hasil tersebut sama dengan skor aroma pada permen jelly rumput laut sebesar 5,6 (cukup). Hasil tersebut tidak berbeda jauh dengan hasil penelitian (Yani 2006) skor aroma pada produk permen jelly yang diperoleh sebesar 5,68 (cukup). Pernyataan tersebut menjelaskan bahwa produk gumdrops puree pepaya memiliki nilai aroma yang sama dengan permen jelly rumput laut.

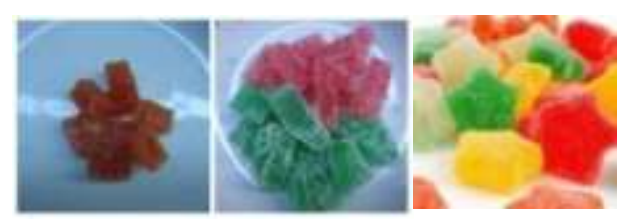

Gambar. 1 Gumdrops Puree Pepaya, Gumdrops dan Permen Jelly

\section{Atribut Aroma}

Atribut aroma memiliki skor kepercayaan (bi) sebesar 3,54 yang artinya cukup, hasil tersebut sama dengan skor aroma pada permen jelly rumput laut sebesar 5,6 (cukup). Hasil tersebut tidak berbeda jauh dengan hasil penelitian (Yani 2006) skor aroma pada produk permen jelly yang diperoleh sebesar 5,68 (cukup). Pernyataan tersebut menjelaskan bahwa produk gumdrops puree pepaya memiliki nilai aroma yang sama dengan permen jelly rumput laut.

\section{Atribut Kepadatan}

Atribut warna skor untuk kepercayaan (bi) sebesar 3,25 (cukup). Pada penelitian (Yani 2006) tidak memasukan atribut kepadatan pada penelitiannya. Produk yang bersifat semi padat memiliki sifat elastik. Sifat elastik akan mengalami perubahan panjang dan bentuk apabila diberi gaya tekan atau gaya tarik dan tidak dapat utuh kembali ke bentuk semula (Andarwulan et.al 2011). Atribut kepadatan pada produk gumdrops puree pepaya memiliki sifat elastik yang cukup, tidak kenyal dan bila diberi gaya tekan tidak merubah bentuk tetapi tidak merubah menjadi panjang, karena tepung agar-agar merupakan sari rumput laut merah, memiliki tekstur gel yang garing dan mudah patah.

\section{Atribut Tekstur}

Atribut tekstur memiliki skor kepercayaan (bi) sebesar 3,53 (cukup), hasil tersebut tidak berbeda jauh dengan penelitian (Yani 2006) yang memiliki skor tekstur permen jelly sebesar 5,7 (cukup). Pernyataan tersebut menjelaskan bahwa produk gumdrops puree pepaya memiliki nilai tekstur yang sama dengan permen jelly rumput laut dan telah diterima oleh konsumen. 


\section{KESIMPULAN DAN IMPLIKASI KEBIJAKAN}

\section{Kesimpulan}

Analisis preferensi pada produk gumdrops puree pepaya dibagi menjadi dua kelompok, yaitu karakteristik responden dan faktor mutu produk Hasil penelitian ini memberikan implikasi penting bagi pengembangan produk selanjutnya. Dengan diketahuinya kelemahan-kelemahan atribut suatu produk, maka produsen dapat memperbaiki dari atribut-atribut tersebut sehingga lebih disukai konsumen. Perbedaan usia dan jenis pekerjaan berpengaruh nyata secara signifikan terhadap tingkat konsumsi. Perbedaan usia mempengaruhi selera konsumen yang berbeda-beda, sedangkan perbedaan jenis pekerjaan akan mempengaruhi pola konsumsi dan gaya hidup.

Berdasarkan skor evaluasi (ei) untuk produk gumdrops atribut warna dan tekstur yang paling besar artinya atribut tersebut lebih disukai oleh konsumen. Pada skor kepercayaan (bi) untuk produk gumdrops puree pepaya skor tertinggi adalah atribut rasa dan aroma, hal ini menunjuka atribut rasa dan aroma lebih disukai oleh konsumen. Hal tersebut dikarenakan rasa dan aroma berasal dari puree pepaya asli tanpa penambahan perisa buah dan pemanis. Skor terkecil kepercayaan (bi) yaitu atribut warna dan kepadatan. Warna gumdrops purre pepaya berasal dari warna buah pepaya asli tanpa penambahan pewarna buatan.

Berdasarkan nilai skor sikap total $(59,1493)$, diketahui bahwa penerimaan produk gumdrops puree pepaya dinilai "Cukup" oleh konsumen, hal ini menjelaskan masih ada yang perlu diperbaiki dari segi warna dan kepadatan. Selain itu perlu adanya penambahan rasa buah-buah yang lain yang dapat menimbulkan warna-warna pada produk gumdrops puree pepaya sehingga akan lebih banyak warna yang berasal dari pewarna alami.

\section{Implikasi Kebijakan}

Hasil penelitian masih ada yang diharapkan oleh konsumen sebagai bahan perbaikan yaitu dari segi warna dan perlu adanya penelitian lanjutan tentang ukuran, bentuk gumdrops puree pepaya dan pengemasan untuk menghasilkan produk yang benar-benar dapat dipasarkan.

\section{Daftar Pustaka}

Bayu F, Arfan. 1999. Analisis Preferensi Konsumen Terhadap Produk Ice Cream Swensen's. [skripsi]. Bogor. Fakultas Teknologi Pertanian. Institute Pertanian Bogor, Bogor.

Biro Pusat Statistik Indonesia 2012. Production of Secondary Food Crops in Indonesia. http://www.bps.go.id/ [ Diakses pada tanggal 13 Maret 2013].

Engel JF, Blackwell GD, Minard PW. 2001. Perilaku Konsumen Jilid I, edisi keenam. Jakarta: Binapura Aksara.

Farisi, A. Kharisman. 2011. Strategi Pengembangan Usaha Pepaya California.Fakultas Ekonomi Dan Manajemen. IPB, Bogor.

Fauzano, Ihsan. 2007. Analisis Preferensi Konsumen Terhadap Bubur Singkong (Manihot esculenta Cran.) Instan Dan Bubur Ubi Jalar (Ipomea batatas L.) Instan. Fakultas Teknologi Pertanian. IPB, Bogor.

Kotler, P. 1997. Manajemen Pemasaran Analisis, Perencanaan, Implementasi dan Pengendalian. Salemba Empat, Jakarta

Kotler, P. 2002. Manajemen Pemasaran (Terjemahan). PT Prenhallindo, Jakarta.

Kotler P. 2005. Manajemen Pemasaran Edisi Kesebelas Jilid 1 dan 2. PT. Jakarta: Indeks Kelompok Gramedia.

Kotler, P dan Keller, Kevin Lane. 2008. Manajemen Pemasaran. Jakarta: Penerbit Erlangga.

Singarimbun M. 2006. Metode Penelitian Survai. Jakarta: PT. Pustaka LP3S Indonesia.

Soegiarto S, Atmadja WS, Mubarok H. 1978. Rumput Laut (Algae) : Manfaat, Potensi dan Usaha Budidaya. Jakarta. Lembaga Oseanologi Nasional; LIPI.

Soekarto ST. 1981. Penilaian Organoleptik. Bogor: Pusbangtepa, Institut Pertanian bogor.

Sumarwan U. 2003. Perilaku Konsumen. Jakarta: Ghalia Indonesia.

Umar H. 2000. Riset Pemasaran dan Perilaku Konsumen. Jakarta: PT. Gramedia. 